\title{
Brain mechanisms underlying the effects of amphetamine on feeding and nonfeeding behaviors: Dissociation and overlap*
}

\author{
SHERWOOD O. COLE $\dagger$ and PATRICIA E. GAY \\ Rutgers University, Camden, New Jersey, 08102
}

\begin{abstract}
Evidence is presented to support the view that there is one major distinction in the brain processes underlying the effects of amphetamine. In reference to nonfeeding behaviors, brain processes underlying the drug's action appear to involve the facilitation of aminergic processes which directly influence behavior or which inhibit cholinergic processes. In contrast, the processes underlying the drug's action on feeding behavior appear to involve a final adrenergic blocking action in the lateral hypothalamus. Although the primary processes underlying the effects of amphetamine on feeding and nonfeeding behavior are basically different, evidence suggests that there is considerable overlap in the complete central systems (primary and modulatory) involved in such mediations. Finally, suggestions for further research are presented which are consistent with these distinctions in central mechanisms.
\end{abstract}

Although the effects of amphetamine on a wide variety of behaviors have been outlined (Cole, 1967), it is difficult to specify, in great detail, the biochemical and/or anatomical substrates mediating the action of the drug. However, evidence does support the general view that there is one major distinction in the brain processes underlying the effects of the drug on behavior. Whereas a more wide-spread facilitation of aminergic processes mediates the effects of amphetamine on nonfeeding behaviors, a basic adrenergic-blocking activity in the lateral hypothalamus is involved in the mediation of the effects on feeding behavior. ${ }^{1}$ Although it has been previously suggested that different sites and/or receptors may be involved in the anorexic and locomotor-stimulating actions of amphetamine (Cole, 1966; Van Rossum \& Simons, 1969), no attempt has been made to review experimental evidence in support of such a distinction or to elaborate this view to cover nonfeeding behaviors other than activity.

The purpose of the present paper is twofold: (1) to present evidence that the primary mediational processes underlying the effects of amphetamine on feeding involve basic differences in biochemical and/or anatomical mechanisms than those underlying the effects of the drug on nonfeeding behaviors; and (2) to demonstrate that, although the primary processes are different, the complete central systems (primary and modulatory) underlying the effects of amphetamine on feeding and nonfeeding behaviors may involve a high degree of functional and anatomical overlap.

*This research was supported, in part, by USPHS Grant MH21247 to Russell C. Leaf and Patricia E. Gay, Principal Investigators.

tReprint requests should be sent to Sherwood O. Cole, Department of Psychology, Rutgers University, Camden, New Tersey 08102 .

\section{PRIMARY MEDIATIONAL PROCESSES Nonfeeding Processes}

Amphetamine is similar in structure to the catecholamines and mimics many of their central effects, including the arousal of systems in conflict with cholinergic inhibitors (Carlton, 1963). Evidence has further pointed out the importance of such aminergic processes to the effects of amphetamine on a variety of nonfeeding performances.

Bovet and Oliverio (1967) and Oliverio $(1967,1968)$ have demonstrated the facilitating effect of amphetamine on avoidance performance inhibited by prolonged trial sessions. Oliverio (1968) has further concluded that catecholamines and central adrenergic processes underlie the effectiveness of the drug in antagonizing the inhibitory reactions occurring during this type of conditioning session. The facilitating effect of amphetamine on more standard conditioned avoidance behavior (Krieckhaus, 1965; Krieckhaus et al, 1965; Barrett et al, 1972) may involve similar processes, since amphetamine has been observed to reverse the conditioned-avoidance-response disruption provoked by reserpine, and 1-dopamine has been observed to potentiate this reversal action by amphetamine (Hanson, 1967). In further support of the drug's facilitation of conditioned avoidance behavior being dependent upon aminergic processes are the findings by Miller et al (1970) that pretreatment with $\alpha$-methyltyrosine (a blocker of norepinephrine synthesis) eliminates amphetamine's facilitation of such behavior, and the findings by Goldberg and Ciofalo (1969) that chemical agents which decrease cholinergic function augment the effect of amphetamine on such behavior. Since both catecholamines and serotonin are required for the alleviation of a deteriorated retention of conditioned avoidance behavior by amphetamine (Roffman \& Lal, 
1972), the aminergic process underlying the facilitating action of amphetamine on conditioned avoidance behavior is apparently complex and involves an interaction of biochemical systems.

Randrup and Munkvod (1967) have demonstrated the presence of amphetamine-induced stereotyped behavior (sniffing, licking, and biting) in a wide variety of species, although such behavior may not be amphetamine specific (Fog, 1969). Since Fog et al (1967) have demonstrated that a complete recovery of amphetamine-induced stereotyped behavior (which had been suppressed by $\alpha$-methyltyrosine) can be effected by an injection of a mixture of dopamine and methylscopolamine (an anticholinergic drug) into the central nervous system, facilitation of aminergic processes appears to be involved in the mediation of such behavior. Not only do the findings of Fog et al (1967) support the importance of brain amines to the production of amphetamine-induced stereotyped behavior, but the authors further were able (by microinjection technique) to demonstrate that the important part of such action is localized in the corpus striatum region. Since adrenergic blocking agents have been observed to act in various ways on the amphetamine-induced stereotyped behavior (Herman, 1967), the aminergic processes underlying this action of the drug again may involve relatively complex biochemical and/or anatomical interactions. The fact that amphetamine has been observed to produce stereotyped behavior in septal-lesioned animals as effectively as it does in septal-sham animals strongly suggests that the septal area is not involved in the aminergic mediation of such action (Novick \& Pihl, 1969; Pihl \& Greenberg, 1969).

By the use of drugs that facilitate and block the action of amphetamine on activity, Sulser et al (1968) concluded that the availability of synthesized brain norepinephrine was essential to the psychomotor-stimulating effects of amphetamine. The findings by Galambos et al (1967), that the anticholinergic agents atropine and benactyzine enhanced the hypermotility caused by amphetamine, are also consistent with the view that central aminergic processes are important in this action of the drug. Since amphetamine has been observed to cause the release of norepinephrine from the amygdala region (Stein \& Wise, 1969), it's possible that noradrenergic processes in the amygdala are basic to the effects of amphetamine on activity. Consistent with this interpretation are the findings by $\mathrm{Cole}^{2}$ that lesions of the corticomedial amygdala attenuate the effects of amphetamine on activity, probably by destroying one of the target sites of the drug for such behavior. Dose-dependent changes in the effect of amphetamine on activity following septal damage (Pihl \& Greenberg, 1969; Carey \& Salim, 1970) do suggest, however, that amygdala-septal interactions (not the amygdala alone) underlie the mediation of the drug's action on such behavior.
Although a facilitation of aminergic brain processes appears to be involved in mediating the effects of amphetamine both on stereotyped behavior and motor activity, it seems that different specific substrates are involved. Dopaminergic processes in the corpus striatum appear to underlie the effects of the drug on stereotyped behavior (Randrup \& Munkvad, 1970, 1972; Fog et al, 1967), whereas noradrenergic processes in the amygdala (and possibly other sites) appear to underlie the hypermotility effects of the drug (Stein \& Wise, 1969). Consistent with this distinction in central aminergic processes is the behavioral distinction that, while smaller doses of amphetamine increase activity with such behavior accompanied by only moderate stereotyped patterns (Ernst, 1967), larger doses of the drug, which produce marked stereotyped behavior, usually result in an accompanying reduction in activity (Pihl \& Greenberg, 1969). Such behavioral changes in the action of amphetamine suggest that larger doses of amphetamine may be required to activate the dopaminergic sites in the corpus striatum which underlie stereotyped behavior.

Not only are the facilitating effects of amphetamine on nonfeeding behaviors apparently mediated by aminergic processes, but inhibitory actions of the drug on certain cholinergically controlled behaviors also appear to involve similar mechanisms. For example, Leaf (1970) has proposed that mouse killing by rats (an example of interspecific aggression) is regulated by a cholinergic brain system, with the modulation of such behavior involving adrenergic amygdaloid sites. Consistent with this assumption is the finding that pilocarpine (a cholinergic drug) will initiate mouse killing in rats that do not kill mice spontaneously (McCarthy, 1966; Vogel \& Leaf, 1972; Wnek \& Leaf, 1973). Amphetamine administered peripherally (Karli, 1958; Horovitz et al, 1965, 1966; Leaf et al, 1969; Gay, 1973; Gay, Leaf, \& Arble, ${ }^{3}$ or directly to the amygdala by way of cannulae (Leaf et al, 1969) blocks mouse killing by rats, probably by causing the release of norepinephrine, which antagonizes the cholinergic processes underlying such behavior. Consistent with this view is the previously mentioned finding by Stein and Wise (1969) that amphetamine produces release of norepinephrine from the amygdala. Since anterior amygdala lesions do not alter significantly the amphetamine blocking of pilocarpine-induced mouse killing by rats (Gay, 1973), the primary target site for the disruptive effects of amphetamine on such behavior may be more posterior in the region of the corticomedial structures surrounding the stria terminalis. One noticeable difference in the mediational process underlying the amphetamine disruption of mouse killing from those processes previously considered is the fact that aminergic facilitation by the drug antagonizes a cholinergically controlled behavior rather than resulting in a direct action on behavior.

On a more general level, Iwata et al (1969) have 
demonstrated the increased effectiveness of amphetamine on certain motor responses in thiamine-deficient rats. Since thiamine deficiency characteristically results in an increase in catecholamine brain levels, the increased effectiveness of amphetamine under such conditions is consistent with the view that catecholamine levels are important to the drug's effect on nonfeeding behaviors. Apparently, the ability of amphetamine to influence various nonfeeding behaviors depends upon the number and degree of interactions of the drug with various central aminergic processes (Maickel et al, 1969). Support for this conclusion has been presented in the form of a 30 -fold variability in the brain level of the drug with different behavioral tasks, with the level as low as $0.38 \mu \mathrm{g} / \mathrm{g}$ for continuous avoidance and as high as $11.92 \mu \mathrm{g} / \mathrm{g}$ for straight-away escape responses (Maickel et al, 1969). Such an emphasis on the number and degree of interactions would provide a tentative explanation of the fact that, although different aminergic processes are involved in the effect of amphetamine on different nonfeeding behaviors, the drug might activate simultaneously more than one behavioral substrate. Of course, such aminergic processes are not amphetamine-specific, but may respond differently to different drugs and stimuli which act selectively on such receptor sites (Anden et al, 1969).

Although the evidence for a facilitation of aminergic processes mediating the effects of amphetamine on nonfeeding behaviors is extensive, one should argue against simplistic hypotheses as an explanation for such mediation (Weiss \& Laties, 1969). In the case where cortical lesions have been employed as a means of investigating the processes underlying the action of amphetamine on matching performance (Glick \& Jarvik, 1970) and discrimination learning (Jonason et al, 1970), one's interpretation of mediational substrates must be further qualified by the behavioral measure employed, the time after surgery at which the drug is administered, and postoperative differences in rate of learning.

\section{Feeding Processes}

Although the action of amphetamine on nonfeeding behaviors involves widespread facilitation of aminergic processes and anatomical sites, the effect of the drug on feeding appears to involve a specific final blocking action on the lateral-hypothalamic adrenergic "feeding center." Thus, not only is the chemical action of the drug in this case basically different from the chemical processes underlying the effect of the drug on nonfeeding behaviors, but the primary site of amphetamine's action is more anatomically specific.

That the basic regulation of feeding behavior is an adrenergic process is supported by the fact that chemical stimulation of the hypothalamus (with adrenergic agents) increases food consumption (Grossman, 1960; Miller, 1965; Booth, 1968), and by the fact that the reduction in feeding resulting from lateral hypothalamic damage can be reversed by the introduction of norepinephrine (Berger et al, 1971). If one holds to the view that amphetamine affects feeding behavior by working in synergism with or by facilitation of adrenergic mechanisms (as is true with nonfeeding behaviors), the drug should increase feeding, since the regulation of feeding is adrenergic. However, the well-established anorexic action of amphetamine is in strong disagreement with this prediction. Previous attempts to reconcile the effects of amphetamine on feeding with evidence from adrenergic mechanisms seem to have taken two primary forms-a competing response view and a peripheral interpretation. Carlton (1963) has suggested that what appears to be amphetamine anorexia may be due to an increase in activation to the degree that responses incompatible with those required in feeding occur and thus result in a decrease in feeding responses. Since adrenergic mechanisms are responsible for an increase in activation produced by amphetamine, this view would allow one to explain the action of the drug on feeding without positing a separate chemical and/or anatomical mechanism for an explanation of feeding behavior. A second view of the mechanism underlying the action of amphetamine on feeding (Mogenson, 1968) emphasizes the peripheral action of the drug which influences glucoreceptors. Although amphetamine does not alter blood glucose levels, it does reduce liver and muscle glycogen. As a consequence, there is an increase of intracellular glucose in hepatic cells which, according to this view, causes gluco-receptors in the liver to signal a state of satiety and thereby decrease food intake. Although such a view may have limited value, amphetamine has been observed to depress eating in the complete absence of peripheral changes in the circulatory system (Nathanson, 1937) and after interruption of nerve pathways regulating the gastrointestinal tract (Harris et al, 1947). These latter findings, along with the reported changes in the effects of amphetamine on feeding following CNS lesions (Cole, 1967) suggest the need for a central interpretation of the drug's action on feeding.

Booth (1968) has presented evidence which suggests that an explanation of the anorexic action of amphetamine in terms of a final activation of adrenergic mechanisms is erroneously formulated. Cannula-guided chemical stimulation of the lateral hypothalamus resulted in a consistency of correlation between the effectiveness of noradrenalin to elicit eating and the effectiveness of amphetamine to depress eating. These results suggest that amphetamine does influence the lateral hypothalamic adrenergic "feeding center" but produces its anorexic action by blocking or disrupting adrenergic feeding activity. Consistent with this interpretation are the findings by Khavari (1969), that administration of amphetamine in the lateral hypothalamus disrupts feeding, and the findings by Carlisle (1964) and by Panksepp and Booth (1973), that lesions of the lateral hypothalamus attenuate the anorexic action of the drug. Basic to the blocking action 
of amphetamine on feeding may be an increase in the threshold of "feeding center" excitability, since the drug has been found to increase the threshold for eating produced by stimulation of the lateral hypothalamus (Miller, 1960; Stark \& Totty, 1967). Additional evidence that the anorexic effects of amphetamine are counteracted by electrical stimulation of the lateral hypothalamus (Thode \& Carlisle, 1968) and that amphetamine decreases the amplitude of elicited lateral hypothalamic activity (Reiter, 1970) also are consistent with the view that the drug depresses feeding by decreasing lateral hypothalmic excitability.

A lateral-hypothalamic-blocking hypothesis would also seem to provide a tentative explanation of the exaggerated effects of amphetamine on feeding following ventromedial hypothalamic lesions (Epstein, 1959; Reynolds, 1959; Stowe \& Miller, 1957) in terms of changing threshold properties of the lateral hypothalamic "feeding center." There is evidence that electrolytic ventromedial hypothalamic lesions produce the typically observed hyperphagic syndrome by the releasing of inhibitory influences through fibers running laterally into the lateral hypothalamus (Anand \& Brobeck, 1951). Thus, the exaggerated effect of amphetamine may be due to changes in the reactive sensitivity of the lateral hypothalamic "feeding center" produced by the release of ventromedial hypothalamic restraint, which, in turn, increases the effectiveness of the drug in raising the lateral hypothalamic threshold of excitability. A similar, but less direct, release of restraint may underlie the exaggerated action of the drug following anterior hypothalamic lesions (Cole, 1966), since fibers of the medial forebrain bundle are located in the anterior hypothalamus and serve important functions in regulating the activity of the lateral hypothalamic "feeding center" (Morgane, 1961a, b). Since Carlisle and Reynolds (1961) observed an exaggerated effect of amphetamine on feeding following brainstem (area postrema) lesions, a similar "release of restraint" on downstream executive functions of feeding is apparently possible as well.

As to the specific biochemical action involved in the amphetamine blocking of activity in the lateral hypothalamic adrenergic "feeding center," no conclusive answer can be given to date. Since Margules (1969, 1970) has suggested that amphetamine may depress feeding by stimulating $\alpha$-adrenergic cells in the ventromedial hypothalamic "satiety center," the blocking action of the drug may be an indirect one through fibers connecting the "satiety center" with the "feeding center." Such a view is similar to the previously proposed explanation of amphetamine anorexia in terms of a "mimicking" of "satiety center" activity (Brobeck et al, 1956) and purports that one adrenergic process (medial hypothalamus) activated by the drug is, in turn, able to antagonize another adrenergic process which regulates feeding (lateral hypothalamus). Although the initial stage in this sequence involves an aminergic facilitation by amphetamine, the final stage still involves the basically unique action of the drug in blocking adrenergic activity. Krebs et al (1960) found that amphetamine increases the firing rate of single neural units in the ventromedial hypothalamus, and Carr and Moore (1969) demonstrated that amphetamine releases norepinephrine from the ventromedial hypothalamus, making such an explanation plausible. However, such a view would predict an attenuation or elimination of the anorexic effect of amphetamine following lesion destruction of the ventromedial target site rather than the exaggerated anorexic effect of the drug that has been found following destruction of this target site (Epstein, 1959; Reynolds, 1959; Stowe \& Miller, 1957). Only one study (Sharp et al, 1962) has reported an attenuation of amphetamine anorexia following ventromedial hypothalamic lesions, and these results may be challenged on the basis of a major difference in the time course used to evaluate the changing effectiveness of the drug (Carlisle, 1964). Although Margules $(1969,1970)$ has suggested that the exaggerated action of amphetamine on feeding following ventromedial hypothalamic lesions is due to a denervation supersensitivity of remaining $\alpha$-adrenergic sites, it is still difficult to see how nontarget sites should be more effective in mediating amphetamine anorexia than would the primary target sites. Rather than the blocking action of amphetamine involving an indirect influence on the "feeding center" by means of ventromedial hypothalamic mimicking, it may involve a direct influence on $\beta$-adrenergic cells in the lateral hypothalamus (Leibowitz, 1970). This view would appear to be more consistent with the findings of Booth (1968), that cannulae-guided stimulation of the lateral hypothalamus by noradrenalin and amphetamine had directionally opposite effects on feeding, and purports that two antagonistic adrenergic processes in the lateral hypothalamus underlie the action of amphetamine on feeding. A direct action of the drug on the lateral hypothalamic "feeding center" also permits one to make certain theoretical distinctions between a depression of feeding resulting from amphetamine and that resulting from an increase in circulatory glucose (Blundell, 1971).

Although specific details of the biochemical action underlying the effect of amphetamine on feeding remain to be worked out, there is little doubt that the net results of such processes is the final blocking of activity in the lateral hypothalamic-adrenergic "feeding center." Such a final adrenergic blocking action makes the central processes underlying the effect of amphetamine on feeding basically different from the aminergic facilitation process or aminergic blocking of cholinergic processes underlying the effects of the drug on nonfeeding behaviors. Furthermore, attempts to correlate amphetamine-induced whole brain changes in aminergic content with changes in feeding (Holtzman \& Jewett, 1971) fail to make these necessary distinctions between a final adrenergic blocking action (which may 
be immediately preceded by an $\alpha$ - or a $\beta$-adrenergic facilitation) and a more general aminergic facilitation underlying the action of the drug on nonfeeding behaviors.

\section{OVERLAP OF CENTRAL SYSTEMS}

Although, as the previous section indicates, the primary processes underlying the effects of ampehtamine on feeding and nonfeeding behaviors involves basic biochemical and anatomical differences, there appears to be considerable overlap in the complete central systems (primary and modulatory) underlying the effects of the drug on such different behaviors.

Lesions of the corticomedial amygdala $\left(\mathrm{Cole}^{2}\right)$ and septal area (Pihl \& Greenberg, 1969; Carey \& Salim, 1970) significantly alter the effect of amphetamine on activity, probably by partially destroying the primary substrates underlying the action of the drug on such behavior. In a somewhat similar manner, lesions of the corticomedial amygdala (Cole, 1973a) and septal area (Carey \& Salim, 1970) alter the effects of amphetamine on feeding, although in the latter case the changes were suggestive and not statistically definitive. The fact that both changes in the effect of amphetamine on activity and feeding have been reported following amygdala and septal damage strongly suggests that there is considerable overlap in the central systems mediating the drug's action on such different behaviors. In light of the evidence that the effect of amphetamine on feeding involves a primary blocking action on the lateral hypothalamic "feeding center" (Booth, 1968), it seems likely that the changes in the effect of the drug on feeding following amygdala and septal damage represent alteration in the modulatory input to such a primary blocking action. Anatomical evidence (Heimer \& Nauta, 1969) suggests that there are extensive connections between the amygdala and hypothalamus, and it has been suggested by Sclafani et al (1970) that the amygdala modulates the more basic regulation of feeding by the hypothalamus through such connections. Also, chemical stimulation of the amygdala and hypothalamus has been observed to produce similar effects on feeding (Grossman, 1960, 1964), which suggests that these sites have some common basis in the regulation of such behavior. In a similar manner, changes in the effect of amphetamine on feeding following septal damage (although less definitive) also may represent alterations in modulating input from other pathways which alter the blocking action of the drug on feeding. While such changes in feeding probably result from damage to input functions which modulate the basic action of the drug on the lateral hypothalamic "feeding center," changes in activity following amygdala and septal lesions probably result from damage to primary adrenergic substrates underlying the action of the drug.

The previously cited evidence in support of an overlap in the central systems underlying the effects of amphetamine on feeding and nonfeeding behaviors should, in no way, imply that such systems are anatomically identical. To the contrary, one might expect the effects of amphetamine on feeding and nonfeeding behavior to be quite independent with the manipulation of central sites other than the amygdala and septal area. Consistent with this assumption are the findings by Cole (1966) that anterior hypothalamic lesions (supra-optic area) alter the effect of amphetamine on feeding but do not alter the effect of the drug on activity. As has been previously suggested (Cole, 1973b), changes in the effect of amphetamine on feeding following such damage are probably due to alternations in the medial forebrain bundle input to the lateral hypothalamic "feeding center" which alter the drug's effectiveness in blocking feeding. The absence of changes in the effect of amphetamine on activity following such damage strongly suggests that this region of the anterior hypothalamus constitutes neither a primary nor a modulatory portion of the central system underlying the action of the drug on such behavior. Since Van Rossum and Simons (1969) have demonstrated that a small dose of amphetamine $(0.33 \mathrm{mg} / \mathrm{kg})$ will increase activity while producing no anorexia, it is likely that different threshold principles assure a functional distinction between feeding and nonfeeding systems even when a high degree of anatomical overlap can be demonstrated.

In further support of the overlap in the central systems underlying the effects of amphetamine on feeding and activity is the behavioral observation that the drug can alter feeding and activity simultaneously (Jennings, 1968; Cole, 1972). Data presented by Van Rossum and Simons (1969) suggest that simultaneous alterations in feeding and activity by amphetamine are dose dependent and are best observed with some intermediate dose level. The statistically significant correlation $(p<.05)$ between an increase in activity and a decrease in food consumption observed in a free-feeding test (Cole, 1972) also suggests that the depressant action of amphetamine on feeding may be due, in part, to the production of behaviors by the drug that are incompatible with or interfere with feeding. However, such a correlation $(r=.49)$, while significant, accounts for only a portion (24\%) of the effect of the drug on feeding. Such a view is similar to that suggested by Carlton (1963), with the exception of one important difference-an emphasis on the degree to which such incompatible behaviors explain the anorexic action of the drug. Whereas Carlton suggests that such incompatible behaviors may be a basic explanation of the anorexic action of amphetamine, the present view would suggest that such incompatible behaviors are superimposed considerations on the more basic regulation of amphetamine anorexia by central sites; i.e., such behaviors may exaggerate amphetamine anorexia, but do not explain such an effect in its entirety.

Brain self-stimulation studies would seem to present a 
very special case for an overlap in the substrates underlying the effects of amphetamine on feeding and nonfeeding behaviors for the following reasons. Amphetamine potentiates the rewarding effects of self-stimulation (a form of nonfeeding behavior), and the brain sites giving the highest reward values overlap or are contiguous with hypothalamic sites basic to the regulation of feeding.

Olds (1962) has reported the effectiveness of amphetamine in sensitizing self-stimulation sites in the anterior hypothalamus. Since lesions of the anterior hypothalamus exaggerate the anorexic properties of amphetamine (Cole, 1966), such sites have already been implicated in the drug's effect on feeding. Anterior hypothalamic positive reinforcement sites which are potentiated by amphetamine appear to overlap with modulating inputs (the medial forebrain bundle) to the "feeding center" which alter the effectiveness of the drug in depressing feeding (Stein, 1968). Other studies (Hoebel, 1965; Hoebel \& Teitelbaum, 1962), which indicate that the hypothalamic control of feeding and self-stimulation overlaps considerably, would suggest that both changes in the amphetamine depression of feeding and in the drug's potentiation of self-stimulation should result from hypothalamic manipulations. Consistent with this assumption are the exaggerated (Epstein, 1959; Reynolds, 1959; Stowe \& Miller, 1957) and attenuated (Carlisle, 1964) effects of amphetamine on feeding following hypothalamic lesions, the reinstatement of blocked hypothalamic self-stimulation by methamphetamine (Poschel \& Ninteman, 1966), and the increase in rate of hypothalamic self-stimulation produced by amphetamine (Gluckman \& Baum, 1969).

The potentiating effect of amphetamine on self-stimulation appears to be due to a reduction in the reward threshold for reinforcing brain sites (Stein, 1964) and not merely due to an increase in low rates of responding (Steiner \& Stokley, 1973). Since the distribution of catecholamines (Olds, 1962) conforms closely to the distribution of reward points (Vogt, 1954) and the positive role of amphetamine in reward mechanisms is counteracted by $\alpha$-methyltyrosine (Poschel \& Ninteman, 1966), it seems appropriate to conclude that such a reduction in the reward threshold of reinforcement depends upon aminergic-facilitation processes. However, there appears to be some need for distinguishing between the short-term potentiating effects and long-run protection effects of amphetamine on such behavior (Olds, 1972), for d-amphetamine gives varying degrees of protection against drugs which suppress self-stimulation behavior. If one holds the view that amphetamine depresses feeding by its blocking action on the lateral hypothalamic "feeding center," the substrates underlying the effects of the drug on self-stimulation and feeding (although overlapping considerably) cannot be anatomically or biochemically identical. To assume they are identical would require one to explain how the drug's action on a single site could potentiate self-stimulation (by a reduction in reward threshold) and block feeding (by an increase in the threshold of excitability).

Other studies in which methamphetamine (Pickens et al, 1967) and amphetamine (Pickens \& Harris, 1968) have been found to serve as self-administered reinforcers suggest some additional facts about the potentiating action of the drug on rewarding self-stimulation. One study (Pickens \& Harris, 1968) indicated a similarity in the reinforcing effects of amphetamine and electrical brain stimulation. The authors found an inverse relationship between the frequency of amphetamine self-administration (infused by chronic jugular catheter) and drug dose as well as a direct relationship between the frequency of responding for self-administration and the value of a fixed ratio schedule of reinforcement. Since food was constantly available and no deprivation was reported, such changes in the self-administration of amphetamine cannot be explained by alterations in feeding motivation and food consumption. What these results do suggest is that the drug mimics the reinforcing properties of brain self-stimulation, thereby acquiring reinforcing properties of its own. Although different biochemical and anatomical substrates are involved, this mimicking of brain self-stimulation systems by amphetamine may be similar, in principle, to the proposed mimicking of the hypothalamic "satiety center" by the drug (Brobeck et al, 1956) which may underlie the drug's blocking action of feeding. Furthermore, such a mimicking action of self-stimulation substrates should, in no way, be inconsistent with the previous suggestion by Stein (1964) that amphetamine reduces the reward threshold of reinforcing brain sites. Whether amphetamine mimics the activity of brain self-stimulation sites or reduces the reward threshold for such sites is moot; the end product is the same-a potentiation of such behavior.

\section{CONCLUDING COMMENTS}

An organization of the effects of amphetamine at the behavioral level would seem to be a realistic undertaking by the employment of a specific guiding principle. One could emphasize a distinction between the depressant action of the drug and the facilitating action of the drug (Cole, 1967). Such a distinction could be behaviorally supported by the depressing effect of the drug on feeding in contrast to the facilitating effect of the drug on intellectual and motor performances, bodily activity, avoidance conditioning, and escape behavior (Cole, 1967). Those instances where such a distinction does not hold might possibly be explained by reversal effects on behavior produced by large doses of amphetamine or by differences in experimental conditions used for evaluating the action of the drug. As an alternative to the above principle is an emphasis on the role that control levels of behavior play in determining the behavioral effects of amphetamine (Dews \& Morse, 
1961; Evans, 1971). Since low-response-reproducing schedules such as fixed-ratio reinforcement with pre-time-out stimulus (Ferster et al, 1962) and DRL and FR reinforcement schedules (Kelleher \& Cook, 1959) are accompanied by an amphetamine-induced increase in food-motivated operant behavior while more typical reinforcement schedules (Cole \& Gay, 1971; Gollub \& Mann, 1969) are accompanied by an amphetamine-induced decrease in such behavior, control levels may be a valuable guideline for organizing the behavioral effects of the drug. Regardless of one's preference, such organizational principles afford a means of summarizing a large body of findings pertaining to the behavioral effects of amphetamine and permit one to set up experimental predictions about the action of the drug.

In contrast, an organization of the central biochemical and/or anatomical substrates underlying the action of amphetamine pose particular problems. Such evidence must be acquired by an indirect manipulation (stimulation, lesioning, recording) of central processes rather than by a direct observation of natural processes, and, in the final analysis, all central manipulations must be meaningfully correlated with behavioral changes before a definitive conclusion can be made about such substrates.

In an attempt to organize evidence pertaining to the central processes underlying the action of amphetamine on behavior, the present paper has chosen a systems approach. Such a strategy allows one to make clear distinctions within systems between primary and modulatory processes while, at the same time, considering the overlap of such systems. Evidence has been presented in support of the view that the primary central biochemical and anatomical processes underlying the effect of amphetamine on feeding are basically different from the primary central processes underlying the effects of the drug on nonfeeding behaviors. However, the complete central systems (primary and modulatory) underlying the action of amphetamine on feeding and nonfeeding behaviors appear to overlap considerably.

In an attempt to provide guidelines for future research which are consistent with the emphasis of the present paper, the following suggestions are offered.

(1) Studies should be designed to determine more conclusively the nature of amphetamine's blocking action on feeding. To this point, one is left with the choice of two possible explanations of such action--mimicking of the hypothalamic "satiety center" which, in turn, may block activity in the "feeding center" and a direct action on the lateral hypothalamic "feeding center." Procedures which isolate portions of the hypothalamus (e.g., surgical knife cuts) may give further insight into what sites or connections within the hypothalamus are essential for the mediation of amphetamine anorexia.

(2) Studies should attempt to determine the degree of independence and/or overlap in the complete central systems underlying the action of amphetamine on feeding and nonfeeding behaviors. This might be accomplished by measuring simultaneously the effects of the drug on feeding and nonfeeding behaviors (e.g., activity) following a systematic plan of central manipulation.

(3) Studies should attempt to ascertain, in greater detail, the aminergic-facilitation processes underlying the action of amphetamine on a variety of nonfeeding behaviors. Since the aminergic processes underlying the drug's action on nonfeeding behaviors are diffuse, an investigation of amphetamine's influence on such behaviors in terms of the number or degree of interactions with aminergic processes may prove to be more fruitful than an attempt to stress biochemical and anatomical detail.

\section{REFERENCES}

Anand, B. K., \& Brobeck, J. R. Hypothalamic control of food intake in rats and cats. Yale Journal of Biology \& Medicine, $1951,24,123-138$.

Anden, N. E., Carlson, A., \& Haggendal, J. Adrenergic mechanisms. Annual Review of Pharmacology, 1969, 9, 119-134.

Barrett, R., Leith, N., \& Ray, O. Permanent facilitation of avoidance behavior by d-amphetamine and scopolamine. Psychopharmacologia, 1972, 25, 321-331.

Berger, B. D., Wise, C. D., \& Stein, L. Norepinephrine: Reversal of anorexia in rats with lateral hypothalamic damage. Science, 1971, 172, 281-284.

Blundell, J. E. Possible mechanism for the effect of anorexic agents on feeding and hoarding behavior in rats. Psychopharmacologia, 1971, 22, 224-229.

Booth, D. A. Amphetamine anorexia by direct action on the adrenergic feeding system of rat hypothalamus. Nature, 1968, 217, 869-870.

Bovet, D., \& Oliverio, A. Decrement of avoidance conditioning performance in inbred mice subjected to prolonged sessions: Performance recovery after rest and amphetamine. Journal of Psychology, 1967, 65, 45-55.

Brobeck, J. R., Larsson, S., \& Reyes, F. A study of electrical activity of the hypothalamic feeding mechanism. Journal of Physiology, 1956, 132, 358-364.

Carey, R. J., \& Salim, A.P. Changes in d-amphetamine reactivity resulting from septal forebrain injury. Physiology \& Behavior, 1970, 5, 133-136.

Carlisle, H. J. Differential effects of amphetamine on food and water intake in rats with lateral hypothalamic lesions. Journal of Comparative \& Physiological Psychology, 1964, 58, 47-54.

Carlisle, H. J., \& Reynolds, R. W. Effect of amphetamine on food intake in rats with brain-stem lesions. American Journal of Physiology, 1961, 201, 965-967.

Carlton, P. L. Cholinergic mechanisms in the control of behavior by the brain. Psychological Review, 1963, 70, 19-39.

Carr, L. A., \& Moore, K. E. Norepinephrine: Release from brain by d-amphetamine in vivo. Science, $1969,164,322-323$.

Cole, S. O. Increased suppression of food intake by amphetamine in rats with anterior hypothalamic lesions. Journal of Comparative \& Physiological Psychology, 1966, 61, 302-305.

Cole, S. O. Experimental effects of amphetamine: A review. Psychological Bulletin, 1967, 68, 81-90.

Cole, S. O. The relationship of amphetamine-induced anorexia and freezing under free-feeding conditions. Pharmacological Research Communications, 1972, 4, 71-76.

Cole, S. O. Changes in amphetamine anorexia following amygdala lesions in rats. Proceedings, 81st Annual Convention, American Psychological Association, 1973a, 1043-1044.

Cole, S. O. Hypothalamic feeding mechanisms and amphetamine anorexia. Psychological Bulletin, 1973b, 79, 13-20.

Cole, S. O., \& Gay, P. E. Interaction of amphetamine and food deprivation on a food-motivated operant. Communications in Behavioral Biology, 1971, 6, 345-347.

Dews, P. B., \& Morse, W. H. Behavioral pharmacology. Annual R eview of Pharmacology, 1961, 1, 145-174.

Epstein, A. Suppression of eating and drinking by amphetamine and other drugs in normal and hyperphagic rats. Journal of Comparative \& Physiological Psychology, 1959, 52, 37-45. 
Ernst A M Mode of action of apomorphine and dexamphetamine on gnawing compulsions in rats. Psychopharmacologia, 1967, 10, 316-323.

Evans, H. L. Behavioral effects of methamphetamine and $\alpha$-methyltyrosine in the rat. Journal of Pharmacology \& Experim ental Therapeutics, 1971, 176, 244-254.

Ferster, C. B., Appel, J. B., \& Hiss, R. A. The effects of drugs on a fixed ratio performance suppressed by a pre-time-out stimulus. Journal of the Experimental Analysis of Behavior, $1962,5,73-88$.

Fog, R. L. Stereotyped and non-stereotyped behavior in rats induced by various stimulant drugs. Psychopharmacologia, 1969, 14, 299-304.

Fog, R. L., Randrup, A., \& Pakkenberg, H. Aminergic mechanisms in corpus striatum and amphetamine-induced stereotyped behavior. Psychopharmacologia, 1967, 11 . 179-183.

Galambos, E., Pfeifer, A. K., Gyorgy, L., \& Molnar, J. Study on the excitation induced by amphetamine, cocaine and $\alpha$-methyltry ptomine. Psychopharmacologia, 1967, 11 , 122-129.

Gay, P. E. Inhibitory effects of pre-and post-test d-amphetamine on mouse killing by rats. Unpublished doctoral dissertation, Rutgers University, 1973 .

Glick, S. D., \& Jarvik, M. E. Differential effects of amphetamine and scopolamine on matching performance of monkeys with lateral frontal lesions. Journal of Comparative \& Physiological Psychology, 1970, 73, 307-313.

Gluckman, M. I., \& Baum, T. The pharmacology of iprindale, a new anti-depressant. Psychopharmacologia, 1969, 15, 169-185.

Goldberg, M. E., \& Ciofolo, V. B. Alteration of the behavioral effects of amphetamine by agents which modify cholinergic functions. Psychopharmacologia, 1969, 14, 142-149.

Gollub, L. R., \& Mann, W. G. The interaction of amphetamine and body weight on a food-reinforced operant. Psychopharmacologia, 1969, 15, 64-72.

Grossman, S. P. Eating or drinking elicited by direct adrenergic or cholinergic stimulation of hypothalamus. Science, 1960 $132,301-302$.

Grossman, S. P. Behavioral effects of chemical stimulation of ventral amygdala. Journal of Comparative \& Physiological Psy chology, 1964, 57, 29-36.

Hanson, L. C. F. Evidence that the central action of $(+)$-amphetamine is mediated via catecholamines. Psychopharmacologia, 1967, 10, 289-297.

Harris, S. C. Ivy, A. C. \& Searle, L. M. The mechanism of amphetamine induced loss of weight. Journal of the American Medical Association, 1947, 134, 1468-1475.

Herman, Z. S. Influence of some psychotropic and adrenergic blocking agents upon amphetamine stereotyped behavior in white rats. Psy chopharmacologia, 1967, 11, 136-142.

Heimer, L., \& Nauta, W. J. H. The hypothalamic distribution of the stria terminalis in the rat. Brain Research, 1969, 13, 284-297.

Hoebel, B. G. Hypothalamic lesions by electrocauterization: Disinhibition of feeding and self-stimulation. Science, 1965 $149,452-453$.

Hoebel, B. G., \& Teitelbaum, P. Hypothalamic control of feeding and self-stimulation. Science, 1962, 135, 375-376.

Holtzman, S. G., \& Jewett, R. E. The role of brain norepinephrine in the anorexic effects of dextroamphetamine and monoamine oxidase inhibitors in the rat. Psychopharmacologia, 1971, 22, 151-161.

Horovitz, Z. P., Ragozzino, P. W., \& Leaf, R. C. Selective block of rat mouse-killing by antidepressants. Life Sciences, 1965, 4 1909-1912.

Horovitz, Z. P. Piala, J. J., High, J, P. Burke, J. C., \& Leaf, R. C. Effects of drugs on the mouse-killing (muricide) test and its relationship to amygdaloid function. International Journal of Neuropharmacology, 1966, 5, 405-411.

Iwata, H. Watanabe, K. Nishikawa, T., \& Ohashi, M. Effects of drugs on behavior, heart rate and catecholamine levels in thiamine deficient rats. European Journal of Pharmacology, $1969,6,83-89$.

Jennings, W. A. Effect of d-amphetamine on open-field behaviors in the rat. Psychological Reports, 1968, 22, 345-346.

Jonason, K. R., Lauber, S. M., Robbins, M. J., Meyer, P. M., \& Meyer, D. R. Effects of amphetamine upon relearning pattern and black-white discriminations following neocortical lesions in rats. Journal of Comparative \& Physiological Psychology, $1970,73,47-55$.

Karli, P. Action de l'amphetamine et de la chlorpromazine sur l'agressivité interspecifique Rat-Souris. Comptes Rendus des Seances de la Societé de Biologie, 1958, 152, 1796-1798.

Kelleher, R. T., \& Cook, L. Effects of d-amphetamine, meprobamate, phenobarbital, mephrenesin, or chlorpromazine on DRL and FR schedules of reinforcement with rats. Journal of the Experimental Analysis of Behavior, 1959, 2, 267.

Khavari, K. A. Effects of central versus intraperitonial d-amphetamine administration on learned behavior. Journal of Comparative \& Physiological Psychology, 1969, 68, 226-234.

Krebs, H., Bindra, D., \& Campbell, J. F. Effects of amphetamine on neural activity in the hypothalamus. Physiology \& Behavior, 1969, 4, 685-691.

Krieckhaus, E. E. Decrements in avoidance behavior following mammillo-thalamic tractotomy in rats and subsequent recovery with d-amphetamine. Journal of Comparative \& Physiological Psychology, 1965, 60, 31-35.

Krieckhaus, E. E. Miller, N. E., \& Zimmerman, P. Reduction of freezing behavior and improvement of shock avoidance by d-amphetamine. Journal of Comparative \& Physiological Psychology, 1965, 60, 36-40.

Leaf, R. C. Pharmacology, limbic regulation, and cortical function. In W. L. Smith (Ed.), Drugs and cerebral function. Springfield: Thomas, 1970. Pp. 201-213.

Leaf, R. C., Learner, L., \& Horovitz, Z. P. The role of the amygdala in the pharmacological and endocrinological manipulation of aggression. In S. Garattini and E. G. Sigg (Eds.), Aggressive behaviour. Amsterdam: Excerpta Medica Foundation, 1969. Pp. 120-131.

Leibowitz, S. F. Hypothalamic $\beta$-adrenergic "satiety" system antagonizes an $\alpha$-adrenergic "hunger" system in rats. Nature, $1970,226,963-964$

Maickel, R. P., Cox, R. H., Miller, F. P., Segal, D. S., \& Russell, R. W. Correlation of brain levels of drugs with behavioral effects. Journal of Pharmacology \& Experimental Therapeutics, 1969, 165, 216-224.

Margules, D. L. Noradrenergic synapses in "perifornical" hypothalamus for the suppression of feeding behavior by satiety. Federation Proceedings, 1969, 28, 641.

Margules, D. L. Alpha-adrenergic receptors in hypothalam us for the suppression of feeding behavior by satiety. Journal of Comparative \& Physiological Psychology, 1970, 73, 1-12.

McCarthy, D. Mouse-killing in rats treated with pilocarpine. Federation Proceedings, 1966, 25, 385 .

Miller, F. P., Cox, R. H., \& Maickel, R. P. The effects of altered $b$ rain norepinephrine levels on continuous avoidance responding and the action of amphetamine. Neuropharmacology, 1970, 9, 511-517.

Miller, N. E. Motivational effects of brain stimulation and drugs. Federation Proceedings, 1960, 19, 846-854.

Miller, N. E. Chemical coding of behavior in the brain. Science, $1965,148,328-338$

Mogenson, G. J. Effects of amphetamine on self-stimulation and induced drinking. Physiology \& Behavior, 1968, 3, 133-136.

Morgane, P. J. Distinct feeding and hunger motivating systems in the lateral hypothalamus of the rat. Science, 1961a, 113, 887-888.

Morgane, P. J. Electrophysiological studies of feeding and satiety centers in the rat. American Journal of Physiology, 1961b, 201, 838-844

Nathanson, M. H. The central action of benzedrine. Journal of the American Medical Association, 1937, 108, 528-531.

Novick, I., \& Pihl, R. Effect of amphetamine on the septal syndrome in rats. Journal of Comparative \& Physiological Psychology, 1969, 68, 220-225.

Olds, J. Hypothalamic substrates of reward. Physiological Review, 1962, 42, 554-604.

Olds, M. E. Alterations by centrally acting drugs of the suppression of self-stimulating behavior in the rat by tetrabenazine, physostigmine, chlorpromazine, and pentobarbital. Psy chopharmacologia, 1972, 25, 299-314.

Oliverio A. Analysis of the "anti-fatigue" activity of amphetamine. Role of the central adrenergic mechanisms. I Farmaco: Edizione Scientifica, 1967, 22, 441-449.

Oliverio, A. Neurohumoral systems and learning. In D. H. Efron (Ed.), Psychopharmacology-A review of progress. Washington, D.C: USPHS, (PHS Publication No. 1836), 1968. Pp. 867-878.

Panksepp, J., \& Booth, D. A. Tolerance in the depression of intake when amphetamine is added to the rat's food. Psychopharmacologia, 1973, 29, 45-54.

Pickens, R., \& Harris, W. C. Self-administration of d-amphetamine by rats. Psychopharmacologia, 1968, 12 158-163.

Pickens, R., Meisch, R., \& McGuire, L. E. Methamphetamine reinforcement in rats. Psychonomic Science, 1967, 8, 371-372.

Pihl, R. O., \& Greenberg, I. The interactive effect of amphetamine on the activity level of rats with lesions in the septum. Psychonomic Science, 1969, 14, 216-217.

Poschel, B. P. H., \& Ninteman, R. W. Hypothalamic self-stimulation: Its suppression by blockade of norepinephrine synthesis and reinstatement by methamphetamine. Life Sciences, 1966, 5, 11-16.

Randrup, A., \& Munkvad, I. Stereotyped activities produced by amphetamine in several animal species and man. Psychopharmacologia, 1967, 11, 300-310.

Randrup, A., \& Munkvad, I. Biochemical, anatomical, and 
psychological investigations of stereotyped behavior induced by amphetamines. In E. Costa and S. Garattini (Eds.), Amphetamines and related compounds. New York: Raven Press, 1970. Pp. 695-713.

Randrup, A., \& Munkvad, I. Mechanisms by which amphetamines produce stereotypy, aggression and other behavioral effects. Psychopharmacologia, 1972, 26 (Supplementum, Collegium Internationale Neuropsychopharmacologicum, VIII C.I.N.P. Congress, Copenhagen, Denmark, August 14-17, 1972), 37 (Abstract).

Reiter, L. Effects of amphetamine on lateral hypothalamic activity in response to amygdaloid stimulation. Federation Proceedings, 1970, 29, 383.

Reynolds, $R$. The effects of amphetamine on food intake in normal and hypothalamic hyperphagic rats. Journal of Comparative \& Physiological Psychology, 1959, 52, 682-684.

Roffman, M., \& Lal, H. Role of brain amines in learning associated with amphetamine state. Psychopharmacologia, 1972, 25, 195-204.

Sclafani, A., Belluzzi, J. D., \& Grossman, S. P. Effects of lesions in the hypothalamus and amygdala on feeding behavior in the rat. Journal of Comparative \& Physiological Psychology, $1970,72,394-403$.

Sharp, J. C., Neilson, H. C., \& Porter, P. B. The effect of amphetamine upon cats with lesions in the ventromedial hypothalamus. Journal of Comparative \& Physiological Psychology, 1962, 55, 198-200.

Stark, P., \& Totty, C. W. Effects of amphetamine on eating elicited by hypothalamic stimulation. Journal of Pharmacology \& Experimental Therapeutics, 1967, 158, 272-278.

Stein, L. Amphetamine and neural reward mechanisms. In $\mathrm{H}$. Steinberg (Ed.), Animal behavior and drug action. London: Churchill, 1964. Pp. 91-113.

Stein, L. Chemistry of reward and punishment. In D. H. Efron (Ed.), Psychopharmacology-A review of progress. Washington, D.C: USPHS, (P.H.S. Publication No. 1836), 1968. Pp. 105-135.

Stein, L \& Wise, D, Release of norepinephrine from hypothalamus and amygdala by rewarding medial forebrain bundle stimulation and amphetamine. Journal of Comparative \& Physiological Psychology, 1969, 67, 189-198.

Steiner, S. S., \& Stokely, S. N. Methamphetamine lowers self-stimulation threshold. Physiological Psychology, 1973, 1 , 161-164.

Stowe, F. R., \& Miller, A. T. The effect of amphetamine on food intake in rats with hypothalamic hyperphagia. Experientia, 1957, 13, 114-115.
Sulser, F., Owens, M. L., Norvich, M. R., \& Dingell, J. V. The relative role of storage and synthesis of brain norepinephrine in the psychomotor stimulation evoked by amphetamine or by desipramine and tetrabenazine. Psychopharmacologia, 1968, 12, 322-332.

Thode, W. P., \& Carlisle, H. J. Effect of lateral hypothalamic stimulation on amphetamine-induced anorexia. Journal of Comparative \& Physiological Psychology, 1968, 66, 547-548.

Van Rossum, J. M., \& Simons, F. Locomotor activity and anorexogenic action. Psychopharmacologia, 1969, 14, 248-254.

Vogel, J. R., \& Leaf, R. C. Initiation of mouse killing in non-killer rats by repeated pilocarpine treatment. Physiology \& Behavior, 1972, 8, 421-424.

Vogt, $M$. The concentration of sympathin in different parts of the central nervous system under normal conditions and after administration of drugs. Journal of Physiology, 1954, 123, 451-481.

Weiss, B., \& Laties, V. G. Behavioral pharmacology and toxicology. Annual Review of Pharmacology, 1969, 9, 297-326.

Wnek, D. J., \& Leaf, R. C. Effects of cholinergic drugs on prey-killing by rodents. Physiology \& Behavior, 1973, 10, 1107-1113.

\section{NOTES}

1. The term "facilitation" merely emphasizes the increased availability of biogenic amines at effective receptor sites and does not attempt to make further distinctions as to whether amphetamine increases release or utilization of such amines or blocks their re-uptake by pre-sy naptic cells.

2. Cole, S. O. Attenuation of the effects of amphetamine on activity following amygdala lesions in rats. Unpublished manuscript.

3. Gay, P. E., Leaf, R. C., \& Arble, F. B. Inhibitory effects of pre- and post-test d-amphetamine on mouse killing by rats. Submitted for publication.

(Received for publication November 20, 1973; accepted December 17, 1973.) 